\title{
Course Allocation System for Lecturers
}

\author{
Fairuz Rauf \\ Faculty of Communication, Visual \\ Art and Computing \\ Universiti Selangor \\ Malaysia
}

\author{
Youagenraj Kalai Selvan \\ Faculty of Communication, Visual \\ Art and Computing \\ Universiti Selangor \\ Malaysia
}

\author{
Zuraidy Adnan \\ Faculty of Communication, Visual \\ Art and Computing \\ Universiti Selangor \\ Malaysia
}

\begin{abstract}
On this project, the purpose of system developing is to ease and smoothen the course allocation process. Moreover, a lot of issues have popped up regarding the manually allocation method such as lecturers could not get the expertise courses to be lectured, more courses given to higher position lecturers and also burden their research timing. According, to the problem the developer has come up with a solution which to develop a course allocation system for lecturers. The developer has set the objectives to provide the lecturers their expertise field course to be lectured and also provide the correct number of courses according to the lecturer position and timing. Regarding, this the developer has done a research study on the similarities of the system which has been developed previously. So that, the developer can make a comparison with the previous system and the system about to be developed. Next, the developer has chosen the Rational Unified Process (RUP) methodology to develop the system because the methodology is the backbone of the system. Moreover, the developer also has done a few data collection using the data collection method. In addition, there are few respondents who have replied and provide the vital information of the user requirement. Next, the developer has developed the basic interfaces of the system which likely will have the interfaces once the system has been developed. Lastly, this project also can used to refer for the futuristic course allocation system development or it also can enhance to a modern system according to user requirement.
\end{abstract}

\section{Keywords}

Date Collection Method, Data Analysis Method, Software Development Method, Alpha Testing.

\section{INTRODUCTION}

The course allocation system for lecturer is being developed to provide ease handling on course given for lecturers. A lot of issue has been developed due to this allocation method which has been conducting manually using a software called Microsoft Excel. All lecturers are having their preferable courses where their expertise field play the most important role on that issue. The lecturer is the biggest guide for the student lecturing in the courses that students taking on the semester. It doesn't mean that all the lecturer can only teach few courses according to their expertise to be lectured for the students but they also can teach all courses which has not on their expertise field. Due to that doing on manual course allocation they could not get the preferred course, due to that a system has to be develop accordingly. The system also minimizes the usage of paperwork and user friendly for the administrators to $\log$ in and edit if any changes required for the course allocation. The system will print out a output of a list stated for lecturers on their preferred course.

\subsection{Background of Study}

University Selangor is having a constraint on course allocations for the lecturers by using manually software such as Microsoft Excel. It effects the lecturer's expertise field which they have done the majoring studies on it. Every lecturer is having their preferable course to be lectured for the student under that course registered by them on the current semester. Some lecturers also doing their research on the time of their work, due to manual allocation of courses it effects their research timing. Some lecturers are also on higher position also getting more courses to be lectured by them. Moreover, they should be getting less courses to be lectured.

Due to this issue happening in University Selangor, developer have proposed a project. This project consist are system which handles the allocation of the courses for the lecturers according to their expertise and their position. It also minimizes the courses given to the higher position lecturers. This system also user friendly and ease the work of the admin office to provide the lecturers their preferable courses. It also authorizes the admin to make changes in the system by adding new courses if any final year students needed.

\subsection{Problem Statement}

The current allocation is being done manually which cause inaccurate on the number of courses given for the lecturer. Other than that, lecturers could not get the preferred course according to their expertise. Lastly, the courses are difficult to manage according to the changes.

\subsection{Objective}

To handle the course allocation for lecturers on their preferred course according to their expertise. Moreover, provide the access for the lecturers to view on the courses assigned. Lastly, to create a system for the administrators to access or $\log$ in and make changes on the course.

\subsection{Scope of Study}

Administration have the full authorization to $\log$ in to the portal to make any changes on the course adding, dropping and also assigning different lecturers if needed. The administration has to create a profile and set the expertise field for each lecturer so the system can detect it to assign the correct number of courses according to their expertise field for the lecturers. The lecturers also can view the portal on the courses assigned for them. If they wanted to make any changes regarding the courses assigned for them. They can refer the management office for the changes to be applied. 
The system can generate the course allocation itself to assign the correct or expertise field courses according to the lecturers according to their profile created by the administrator in the system. The administration office has to provide the information to the system by creating a profile for each lecturer so the system can detect the expertise field for each lecturer. It also generates the number of courses assigned to the lecturers according to their position. It also allows only administration office to $\log$ in with a specific username and password to make any changes to the allocation.

\subsection{Significance of Project}

The system is developed to ease the administration office work for the course allocation on the semester. This system is also giving priority for the lecturers on the expertise field courses to be lectured for the students who registered the courses on the semester. The system also helps on the higher position lecturers to receive on minimum number of courses which can lower their wok burden. It also helps on the research lecturers to by giving low amount of courses assign according to the profile created on the system. It authorizes the administration only to make any changes manually for the allocation part by adding, dropping or change the lecturer for the courses, if any students or management requested to add or drop the courses. Moreover, the system will be online basis where the lecturers and administrator can access the system anytime and anywhere.

\section{LITERATURE REVIEW}

The education management refers to improvement of the learning and teaching processes. It also provides the idea of management education flow of an automated system rather than transforming it. Information technology is being used to automate the delivery of the information to the users. (Jarvenpaa, 1995) From this article, the conclusion is to improvise the education management from the current situation to be automated to help the users to receive the information.

In addition, another article is focus on a unique experience specifically on a teaching tools or method which flows under the design of the education management. It also provides the evaluation of sustainability in management of education which is providing consistency to integrate the level of education. (Raufflet, 2015) From this article, the conclusion is education management is a design for the teaching or method used to provide the skills on learning the teaching.

Moreover, the education management should be upgraded the flow of teaching learning skills through the design of the education management system. Lastly, the evaluation also provides information to improvise the teaching method. In addition, the literature review has been conducting by using the information's from few articles to collect the ideas of the previous part on the education management and improvise it and to provide the efficiency and consistent for the system development process. Moreover, it also the information from the sources are correspond to the objectives of this project, which are being developed by the developer.

\subsection{IT Education Management}

The is a trend of IT certification which provided for the secondary and post-secondary institutions student to drive them to viable skills of Information Technology part to provide the work force and knowledge needed for the management handling and also to make them continue for higher studies. (Zirkle, 2005) In addition, the journal provides the information for the education management where it runs under the design of Information Technology to manage it and improvise it.

Moreover, the information retrieved from the journal provide information to guide an individual on theory learning process to manage a management of an education. Next, the student also need an exposure on a real-time management to gain experience to handle the management processes and also provide opportunities for them to continue their education on the related field to gain more theoretical studies on Information Technology and the management handling.

Education management are also improvising to an automated system to a new generation of management handling. Information Technology are taking more intention on most of the education management sectors due to that more professional IT skilled individual are needed for the management sectors.

\subsection{Challenges of education management}

The pressure impacted by the management is from external business and also the barriers appears from a series of organizational resources and individual factors according to a journal. (Doherty, 2015) The journal provides a vital information of the range of external pressures which attacks the management with a great influence on the design of the management. Next, the first pressure which impact on the education that weakens the moral responsibility on an individual where it could destroy their future by leading them to the impropriate activities such as drug, theft and a lot more.

Secondly, is employer-led pressure which can impact the management orientation and could lead to diminish the management to reassembly a new management. The decision taken by each leader of the management should be more precise and effective for the future concern of education of each individual and the management. Lastly, is the pressure for marketing their education schools or universities which help them to attract the customers or individuals to enroll in the education schools. In addition, this is the major factor of pressure which the management have to handle because it provides the financial part for the education organization to sustain its position.

\subsection{Importance of Course Allocation System on Education Industry}

The distance of education started with the CCTV technology, which evolved completely into online courses which surprisingly online education has emerged to major form of ebusiness. (Madan, 2007) The journal provides information of the evolvement of education system from manual methods to automated system. In addition, the course allocation system is more vital important part because it provides the student to get the lecturing from the specify lecturers on the related course field and also the lecturers can get the preferred course on their expertise field of study.

Moreover, the online studies have become a part of business profit to a certain part of business industry which managing the education management due that all the syllabus has evolve from manual to digital phase to enhance the technology in education industry. Lastly, the enhanced allocation system is beneficial for the futuristic students to develop their education an also sustain the education management handing. 


\section{METHODOLOGY}

This chapter provides the methods used to identify and help the developer on the development of system or software for their client. Moreover, there two parts of method used for the development of the system which are software development method and data collection method. For the software development method there are few methodologies such as rational unified process (RUP), prototype and many more to be chosen by the developer to develop and produce the system for the clients. So, the developer has to choose the methodology wisely according to their system needs and for the future enhancement of the system.

For this project, the methodology chosen for the development of the system is Rational Unified Process (RUP). RUP method is an object-oriented methodology which used for online system developing. In addition, the developer rectifies and chose this methodology to help on the development stages of the system. RUP method consists of four phases which are inception phase, elaboration phase, construction phase and transition phase

In addition, the data collection method also has a few methods to obtain the source of requirement such as the questionnaire and interview. The method chosen by the developer for gathering the information is questionnaire and interview.

\subsection{Data Collection Methods}

The data collection method is used to collect the information from the user. The method used for this part are questionnaire and interview. The questionnaire is a set of questions about the system will be distributed to the lecturers and administration office staff who will be the user for the course allocation system users. The developer performs this method to recognize the real problem faced by the users in the current course allocation method, according to that the developer will hand in the best solution by providing their clients with the possible course allocation system to minimize the errors or inconsistency of data.

\subsection{Data Analysis Method}

Data analysis method is an evaluation of data which has been collected from the data collection method such as questionnaires and interview. It also helps to identify the errors occurred in the existing data collected. The data will be classified into few types of variable categories. After the classification of variable, it will have analyzed by focusing on a variable and also the approach method of frequency and diagrams. For this project, the developer suggests to apply this approach to rectify the analysis method and also the best solution for the diagrams is histogram or pie chart.

\subsection{Software Development Methods}

Software development method is a process life cycle of a software or system and also the methodology of system development. This part consists of few methodologies such as Rational Process Unified (RUP), waterfall and many more. So, the developer has to choose the methodology according to development and requirement of the project. In this project, the developer has chosen the Rational Unified Process (RUP) to develop the system which consists of four phases of developing stages.

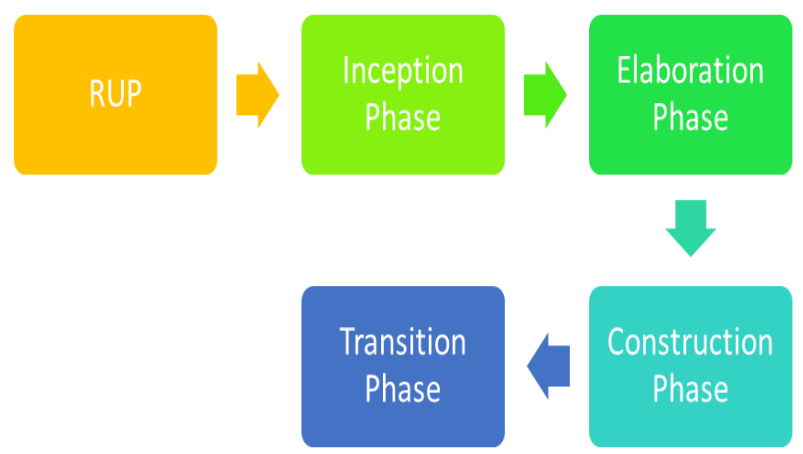

Figure 1: RUP Process Stages of Developing

\section{ANALYSIS}

On this chapter, the developer has to do an analysis of the system which is being on the development progress. The developers have to identify the user requirement by conducting a few methods from the previous chapter such as data collection method. In addition, the developer will use the questionnaire and interview methods results to compare and identify the user requirement. The developer has target for the questionnaire are the lecturers of FCVAC and for the interview session the developer has consulted the Assistance Registrar and the Deputy Dean Academic of FCVAC. Moreover, the user requirement is the most important and vital information for the development of the system. Next, the system requirement also plays an important role on this chapter which need to be identified by the developer using the user requirement.

\subsection{User Requirement}

User requirement is an information given by the users for the development of a system which they need by their own desire looks and accessibilities. So, the developer has to conduct a few methods to rectify the information from the users. The methods used by the developer are questionnaire and interview.

\section{DESIGN}

On this chapter, the developer will design the diagrams of the system which helps on the development of the system. In addition, the diagrams will be the backbone of the system which will guide the developer to develop the system in correct path. Moreover, the developer has to design the interface of the system according to the user requirement. Next, the interface which design by the developer will be the frontline of the look on the system.

From the previous chapters, the developer already identified the user requirement which help on the designing part and also identify the other previous allocation system. Next, the use case diagram which the developer illustrate helps to identify the activities or tasks perform by each user in the system. In addition, the activity diagram need to be illustrated accordingly to the use case diagram which have been drawn.

Moreover, the entity relation diagram (ERD) illustrated to view the relationship on the database and the system. ERD diagram is important for the development of the database for the system. Lastly, the network architecture design is needed to show the flow of the web base system and provide the information on how it's flowing to the internet. 


\subsection{Interface Design}

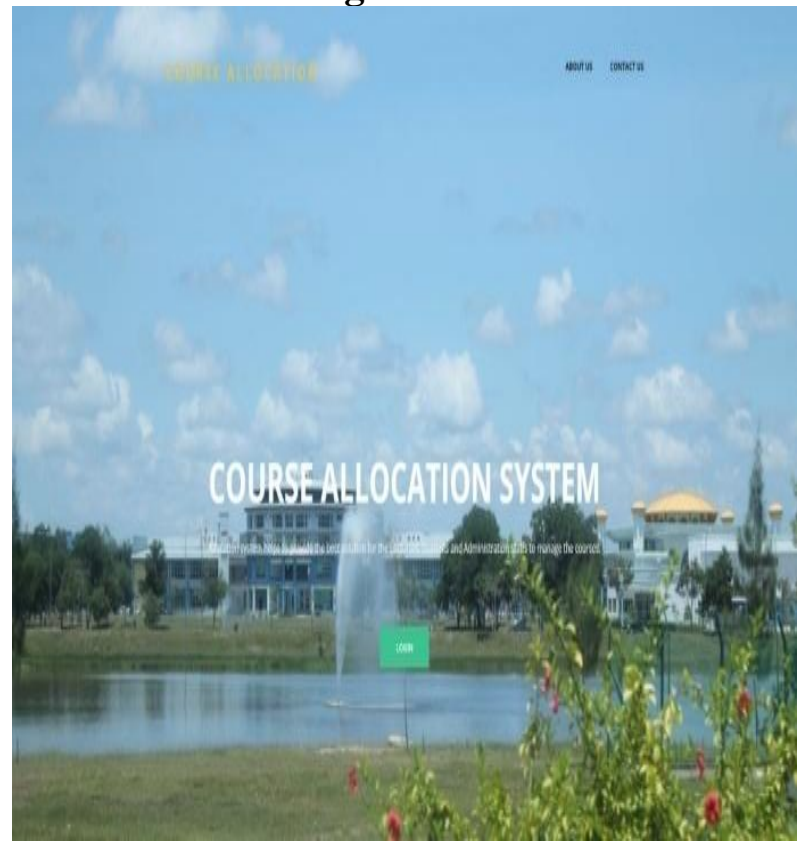

Figure 2: Home Page

Figure 2 shows the home page for this project, is to shown the title of the system and also provide links to the other pages to be viewed. The background is also in the picture of the main chancellery where the main management center hub of the Bestari Jaya campus.

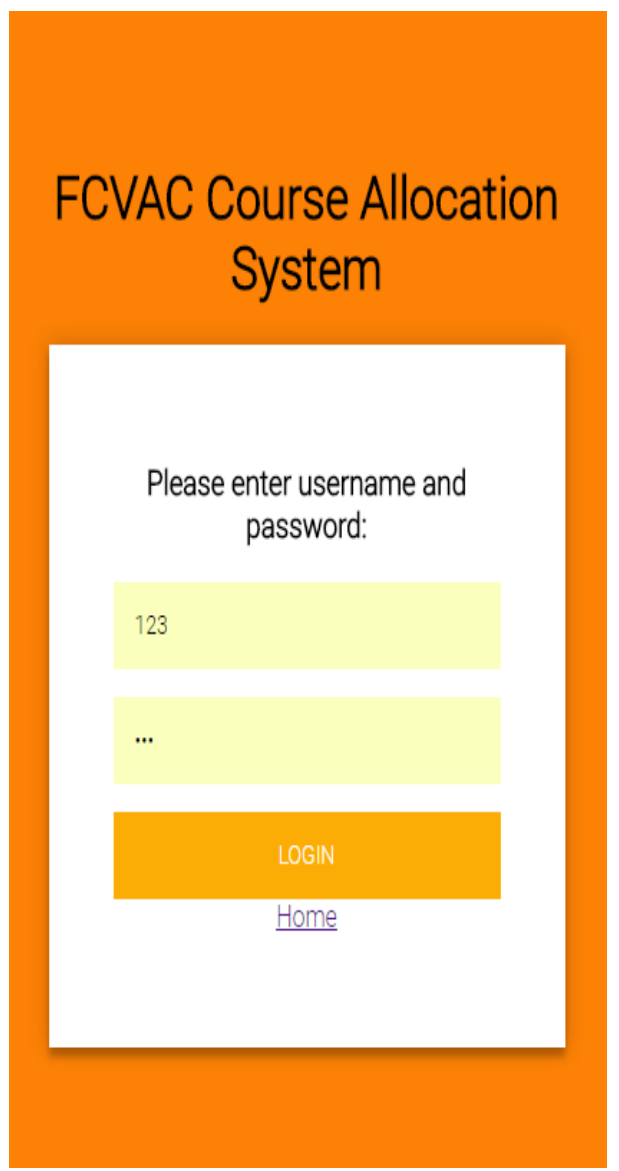

Figure 3: Administrator Login Page
Figure 3 shows the administrator login page for this project the log in page allows the administrator to enter the portal to make the changes on the course allocation system if needed to add or remove any courses and also can change the lecturer teaching on the courses if the lecturer not interested to teach the course.

\subsection{System Design}

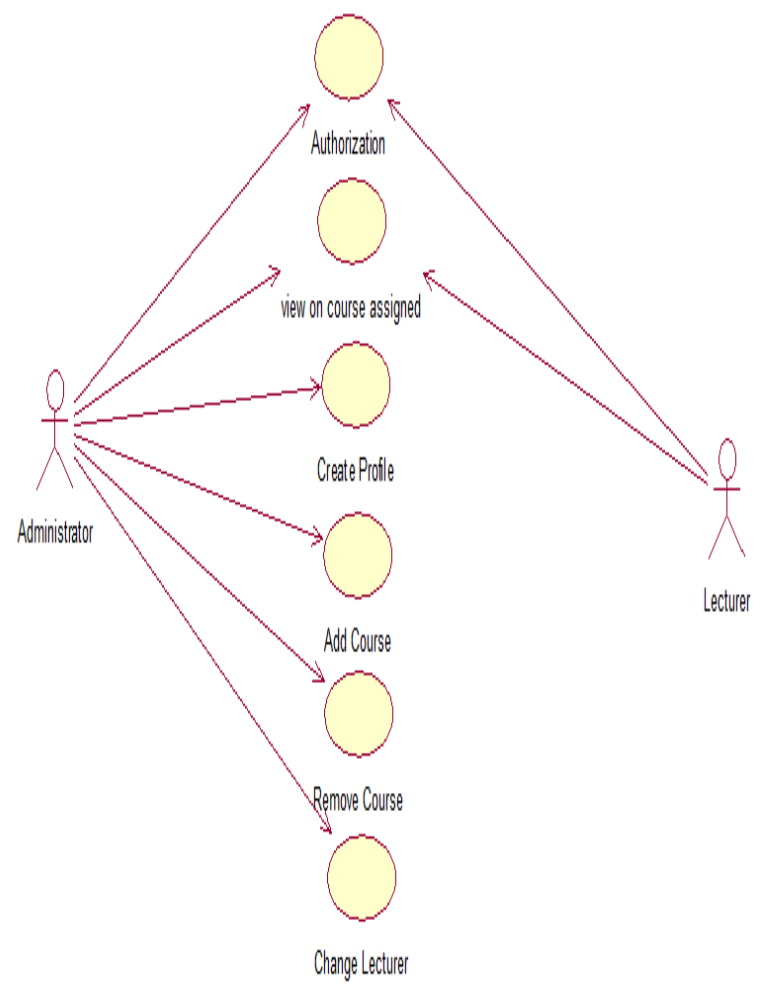

Figure 4: Use Case Diagram

Figure 4 shows the use case diagram. This use case diagram helps the developer to develop the system accordingly. Moreover, the administrator can access the portal with full access because administrator is the only user that has the full authority to make any changes if given orders from the management. Lecturers only can view their profile and the courses allocated for them.

\section{IMPLEMENTATION AND TESTING}

In this stage, the complete system shall be explained. In implementation, the design software used for purpose of the design and the constraints or the difficulties on performance and efficiency are also addressed. Moreover, the implementation is also a way toward putting an activity for the figured arrangement and testing is to assess whether the application and its component work, collaborate appropriately with each other and take after the client prerequisites. In testing, functionalities are graphed according to testing respectively.

\subsection{Implementation}

In implementation, it will portray the development tools that have been utilized as a part of developing this project. It is a post-procedure to ensure everything is working. Implementation stage in this project contain the development process. Development tools that been used in this project are 
NotePad++, Xampp Controller and Adobe Photoshop NotePad++ are being used as a platform to develop the source code for the interfaces of the system. Other than that, the Xampp Controller are used to develop the database in localhost to support and store data for the course allocation system. It also been used as a local server to generate the data's stored in. In between, the Xampp Controller will collaborate with NotePad++ to connect the source code with the databases to provide the data for the system. Lastly, Adobe Photoshop are being used to create and edit a picture used in the one of the interface of the system to look more attractive for the user.

\subsection{Testing}

Testing stage will ensure that the product will have the capacity to execute before be discharging it to the users. This project is already tested using beta testing because it can give a better experience to any users to use it. The test will consider what is should have been change and adjustment that will make the course allocation system to be presented to the client. The testing will likewise have the capacity to discover and limit the bugs and mistakes that are accessible in the system. Alpha testing is a kind of acknowledgment testing performed to identify every single conceivable issue or bugs before discharging the item to ordinary clients. The concentration of this testing is to simulate real clients. The point is to complete the tasks that a run of the typical client may perform. Alpha testing is completed in a lab environment and for the most part the analyzers are inward representatives of the association. To put it as basic as could be expected under the circumstances, this sort of testing is called alpha simply because it is done early on, near the end of the development of the software.

Alpha testing is conducted by the developer to his client to get the feedback of his client about the system that has been developed. Moreover, the client has participated by testing the system such as by viewing the interfaces of the system and test the functionality of each functions available in the system. Other than that, the client also tested the system whether it is user friendly or not. Lastly, the opinions provided by the client are positively taken by the developer to consider in future enhancement

\section{CONCLUSION}

On this chapter, the developer has to conclude about the system development and provide the information on how the development works according to the researches done. Next, the information of the development will be retrieved from the previous chapters which the developer has done. The developer has to include the most important parts of the course allocation system project in this chapter such as the problem statement, objectives and user requirement. In addition, the system developed should be user friendly and efficiently allocate the courses for the lecturers and to be used by the staffs of FCVAC.

\subsection{CONCLUSION}

On this project, the conclusion that can be observe is a system has to be developed for Faculty of Communication, Visual Art and Computing (FCVAC) of Universiti Selangor (UNISEL) to help the management to handle and ease the job of course allocation for the lecturers and students. The faculty is having limitations on allocating courses for the lectures The current allocation is being done manually which provide the lecturers courses to be lectured differently from their expertise.
The developer has done a few researches and case study to compare the system which will be developed soon for the faculty. The developer has observed the a few articles and journal to done the literature review chapter which consist the contents of the system conducting for the management. The case study, also provide a vital information of the similarities of the system will is being developed. The developer has done the comparisons of a few allocation system which provide the guidance to develop the system in the according path.

Next, the developer has chosen the Rational Unified Process (RUP) methodology on chapter research methodology which will be the skeleton of the system. The developer also provides the information of the data collection method which the developer will conduct to rectify the user requirements. Moreover, the developer has given out the questionnaires to the lecturers and also interview the Assistant Registrar, Deputy Dean Academic and Head of Department of FCVAC. In addition, the result has been shown on the following chapter and proven the user requirement.

The chapter of design the developer has shown the diagrams of the system which consists of Use Case, Entity Relation diagram, Sequence, Activity and Network Architecture Diagram. Moreover, the developer also shown the interface of the system which will be developed for the FCVAC and provide the information of the system designs.

Lastly, on the chapter of implementation and testing the developer have conducted alpha testing and also provided a sample of coding on implementation part to ensure that the requirement is met.

\subsection{Future works}

This project can be a guidance, for the futuristic research where other users or people can find through vital information for their project or thesis writing. The developer of course allocation system project also has done research on previously developed system in literature review and provide the information and also the similarity comparison of the systems. This project, can be helpful for future development of allocation system. The course allocation system also can be more specify on different modules by oncoming final year students.

\section{REFERENCES}

[1] Bougie, P. (2012). Web-Based Classroom Allocation System.

[2] Doherty, B. (2015). The business case and barriers for responsible management education in business schools. Management Development, 34-60.

[3] Faizul Navi Khan, K. G. (2013). Cost Optimization Technique of Task Allocation in Heterogeneous Distributed Computing System. Advanced Networking and Applications, 1913-1916.

[4] Franz Diebold, H. A. (2013). Course Allocation via Stable Matching. Department of Informatics.

[5] Jarvenpaa, D. E. (1995). The Use of Information Technology to Enhance Management School Education: A Theoretical View. 265-291.

[6] Latinopoulos. (2014). Using A Market-Type Allocation System To Confront Water Scarcity: An Inter-District Approach In Greece. Global NEST Journal. 
International Journal of Computer Applications (0975 - 8887)

Volume 180-No.22, February 2018

[7] Madan, J. S. (2007). Developing and Delivering Online Courses. E-Business Process Management: Technologies and Solutions, 231-249.

[8] Raufflet, P. S. (2015). Sustainability in higher education: a systematic review with focus on management education. Cleaner Production, 22-33.

[9] Shuang Rong, W. L. (2015). Optimal Allocation of Thermal-Electric Decoupling Systems Based on the
National Economy by an Improved Conjugate Gradient Method. Energies.

[10] Zirkle, M. H. (2005). Information Technology StudentBased Certification in Formal Education Settings: Who Benefits and What is Needed. Information Technology Education 